\title{
CORRECTION
}

View Article Online

View Journal | View Issue
W) Check for updates

Cite this: J. Anal. At. Spectrom., 2020, 35, 1504

DOI: 10.1039/d0ja90045a

rsc.li/jaas

\section{Correction: Interference correction for laser- induced breakdown spectroscopy using a deconvolution algorithm}

\author{
Kun Liu, ${ }^{a}$ Ran Zhou, ${ }^{a}$ Wen Zhang, ${ }^{a}$ Zhiyang Tang, ${ }^{a}$ Jiujiang Yan, ${ }^{a}$ Ming Lv, ${ }^{* a}$
} Xiangyou $\mathrm{Li}^{a}$ Yongfeng $\mathrm{Lu}^{\mathrm{b}}$ and Xiaoyan Zeng ${ }^{\mathrm{a}}$

Correction for 'Interference correction for laser-induced breakdown spectroscopy using a deconvolution algorithm' by Kun Liu et al., J. Anal. At. Spectrom., 2020, 35, 762-766, DOI: 10.1039/C9JA00383E.

The authors regret an error in the affiliation of one of the authors, Yongfeng Lu, in the original manuscript. The correct affiliation is: University of Nebraska-Lincoln (UNL) and not Wuhan National Laboratory for Optoelectronics (WNLO) at the Huazhong University of Science and Technology (HUST). The corrected list of authors and affiliations for this paper is as shown above.

The Royal Society of Chemistry apologises for these errors and any consequent inconvenience to authors and readers. 